\title{
ПОДГОТОВКА, ПЕРЕПОДГОТОВКА И ПОВЫШЕНИЕ КВАЛИФИКАЦИИ КАДРОВ В УСЛОВИЯХ РЫНОЧНОЙ ЭКОНОМИКИ
}

\author{
(c) 2019 Крепс Тамара Владимировна \\ кандидат педагогических наук, доцент кафедры туристского и гостиничного бизнеса \\ Южный Институт Менеджмента \\ Россия, 350040, г. Краснодар, ул. Ставропольская, 216 \\ E-mail: tamara.nesterencko@yandex.ru \\ (c) 2019 Шабанова Татьяна Николаевна \\ преподаватель \\ Гуманитарный колледж \\ Кубанский государственный университет физической культуры, спорта и туризма \\ 350000, г. Краснодар, улица Янковского, 116 \\ E-mail: t-shabanova1989@yandex.ru
}

Рассмотрена актуальная статистика, отражающая современный уровень востребованности кадров в рыночной экономике. Обоснован тезис о том, что в настоящее время востребованный на рыке труда специалист - это субъект, который не только имеет соответствующее базовое профессиональное образование, но и способен к постоянному повышению своего квалификационного уровня.

Ключевые слова: кадры, переподготовка, подготовка кадров, рыночная экономика, рынок труда, квалификация, востребованность, кадровый потенциал.

C теоретико-методологических позиций П.А. Сорокина [1], А. Турена [2], И.Е. Калабихиной [3], Т.И. Заславской и Т.Н. Шабановой [4] трудовые ресурсы, наряду с землей и капиталом, являются факторами производства. Будучи товаром, трудовые ресурсы являются подвижными: человек всегда заинтересован максимально эффективно реализовать свои способности и получить соответствующего объема доход. Тематическое поле данной аналитической статьи - «Подготовка, переподготовка и повышение квалификации кадров в условиях рыночной экономики» - представляется исключительно актуальным в силу комплекса взаимосвязанных причин.

Во-первых, рыночная экономика определяется динамикой спроса и предложения на рынке труда, следовательно, для того, чтобы быть востребованным специалистом, в котором заинтересован потенциальный работодатель, следует последовательно повышать собственный профессиональный уровень, степень квалификации.

Во-вторых, объективным является процесс устаревания знания: то, что ранее было «инновацией» сегодня трактуется как естественный факт. Для того, чтобы отвечать требованиям времени целесообразно стремиться к сохране- нию восприимчивости к новым технологиям, к аспектам конкретной профессии.

B-третьих, возникают новые профессии, активно реализуется процесс «универсализации»: сегодня работодатель все чаще заинтересован в том, чтобы единственный сотрудник мог реализовать множественный функционал в смежных профессиональных областях.

Обратимся к понятийному аппарату, приведем ряд определений центральных категорий очерченного тематического поля.

Подготовка кадров П.И. Ананченковой и B.М. Константиновым [5], Г.Г. Вуковичем [6] трактуется в контексте рыночной экономики, как комплексный системный (образовательный в своей сути) процесс передачи, трансляции определенного спектра профессиональных знаний в отношении круга заинтересованных в этом субъектов.

Значимым итогом процесса подготовки кадров является формирование профессиональный знаний и подготовки, которая, однако, носит теоретико-методологический характер. В условиях рынка - что естественно в силу конкуренции - подобного рода знания требуют накопления дополнительного практического опыта, совокупности практических навыков, умений. 
Переподготовка кадров - это процесс обучения кадров, цель которого заключается в получении ими новых навыков, профессиональных знаний, которые отвечают быстро меняющимся требованиям рынка труда. Фактически переподготовка - это обучение уже имеющих профессию специалистов в целях формирования у них круга актуальных востребованных потенциальным (либо фактическим - если переподготовка осуществляется внутри предприятия, организации) работодателем. Результат переподготовки - получение субъектом новой профессии.

Повышение квалификации работников - это обучение, направленное на последовательное совершенствование профессиональных знаний, умений и навыков мастерства по имеющимся профессиям.

P.А. Фатхутдинов [7], М.Л. Груздева [8], А.Н. Агаева и М.Е. Ледовская [9] изучили систему повышения квалификации в России и за рубежом, сложившуюся в организациях, включающую:

- профессиональные курсы;

- школы передовых приемов и методов работы;

- курсы руководителей;

- самостоятельное обучение.

Фактическим результатом процесса повышения квалификации является выход работников на качественно новый уровень их профессионального мастерства и формирование у них наиболее востребованных навыков, знаний, умений - того, что необходимо для реализации профессиональных обязанностей на более высоком качественном уровне.

Что обуславливает необходимость переподготовки кадров, повышения уровня их квалификации? При ответе на этот вопрос, отметим следующее.

По данным Росстата уровень занятости населения (отношение численности занятого населения к общей численности населения в возрасте 15 лет и старше) в ноябре 2018 г. составил $59,9 \%$, в возрасте $15-72$ лет $-65,7 \%$ [10].

Вместе с тем - и этот факт представляется носящим объективный характер - имеют место комплексные проблемы трудоустройства выпускников вузов, которые определены комплексом ниже проанализированных аспектов.

Во-первых, в отечественной практике к настоящему времени не выработано эффективного и устойчивого механизма, который бы позволил бы сопоставить рынок труда с одной стороны (в условиях кратко- и среднесрочного планирования и прогнозирования) и деятельность средних и высших учебных заведений. Это приводит к дисбалансу, когда рынок труда не нуждается в том количестве выпускников, к примеру, экономических специальностей, которые ежегодно заканчивает соответствующие учебные заведения и молодые специалисты остается невостребованным [11].

Во-вторых, собственно рыночный механизм хозяйствования как таковой усугубляет процессы безработицы, возникающей как следствие переориентации субъектов хозяйствования, их закрытия в результате банкротства и неплатежеспособности. Часто при таких ситуациях обвала рынка выпускники вузов теряют работу. Тот же рыночный механизм вызывает феномен вынужденной безработицы, то есть безработицы, вызванной «простоем» субъекта хозяйствования вследствие отсутствия сырья, энергии, комплектующих [12].

B-третьих, имеет место первичная безработица как ситуация, когда выпускники вузов не могут найти работу по специальности, что заставляет их либо оставлять профессию, либо длительное время заниматься ее поиском. В исследованиях А.С. Чанышева [13] и А.В. Золотова [14] рассматривается фактор частичной принудительной безработицы, вызванной сокращенным рабочим днем или сокращенной рабочей неделей. Это приводит к тому, что даже формально трудоустроенный выпускник не всегда в полной мере задействован на своем рабочем месте.

Альтернатива - процесс переподготовки: на базе уже имеющейся профессии субъекты получают новую, в большинстве случаев смежную. Что, в конечном счете, позволяет им существенным образом повысить свою потенциальную востребованность на рынке труда.

Таким образом, можно сделать вывод: выше сформулированных аспекты обуславливают объективную необходимость процессов переподготовки кадров, постоянного повышения их квалификационного уровня.

В целях анализа состояния подготовки, переподготовки и повышения квалификации кадров в ноябре и декабре 2018 г. было проведено социологическое исследование. Всего обследовано 45 предприятий г. Краснодара, из опрошенных 282 сотрудников 45 - HR-менеджеры или работники 
службы управления персоналом. Периодичность повышения квалификации в значительной степени зависит от специфики деятельности работника. Однако, с учетом периодичности профессионального обучения в нашей стране, каждый работник имеет возможность пройти переподготовку или повысить квалификацию как минимум один раз в пять лет. Распределение исследованных предприятий по количеству работников, прошедших подготовку, переподготовку и повышение квалификации за последние пять лет, представлено на рисунке. Согласно методике исследования С.П. Дырина [15] для удобства подсчета процентные данные округлены.

Таким образом, непрерывное профессиональное обучение доступно большинству опрошенных работников, однако на нескольких предприятиях учет статистики профессиональной подготовки и переподготовки штатных сотрудников вообще не ведется.

Обучение и переподготовка работников часто связаны с изменениями в области информационных технологий или с изменением законодательной базы. Получается, что профессиональное развитие является, прежде всего, следствием изменений в профессиональной деятельности, а не стремлением освоить перспективные технологии на будущее. Таким образом, согласно исследованиям Э.Т. Бабаевой [16], отсутствует прогностически-технократический подход, когда содержание и характер переподготовки и повышение квалификации затрагивает технологии, размаривающиеся в возможностях реального внедрения в будущем.
Методы профессионального обучения условно можно разделить на две группы: обучение непосредственно на рабочем месте и вне его, например, на предприятиях аналогичного профиля, ко второй группе можно отнести выездные совещания по обмену опытом.

Также проведенный опрос 282 работников показал, что превалирующее большинство (почти 90\% опрошенных) при повышении квалификации или переподготовки движет негативный стимул - страх лишиться премии, потерять в заработной плате, а то и потерять рабочее место. Только 28 работников - одна десятая опрошенных, причем коммерческих предприятий, рассматривают непрерывное профессиональное обучение как позитивно направленный стимул, отмечая, прежде всего, надбавку в заработной плате, а также более благоприятные условия труда и карьерный рост.

Важен и тот факт, что на всех участвующих в исследовании предприятиях практикуется профессиональное обучение за счет денежных средств сотрудников. На тридцати предприятиях - работники оплачивают как минимум 40\% от полной стоимости повышения квалификации. А «отсутствие статистики издержек, на основании которой осуществляется анализ эффективности профессионального развития, является одной из особенностей российского управления персоналом» по мнению С.П. Дырина [17].

Рыночная экономика, в контексте занятости населения, актуализирует последовательное внедрение в практику деятельности по управлению персоналом принцип подбора кадров

\section{Число предприятий}

Статистика отсутствует

Профессиональная подготовка не ведется

$$
\begin{array}{r}
\text { Менее } 10 \% \text { работников } \\
10 \%-30 \% \text { работников } \\
30 \%-50 \% \text { работников } \\
50 \%-70 \% \text { работников } \\
70 \%-90 \% \text { работников } \\
90 \%-100 \% \text { работников }
\end{array}
$$

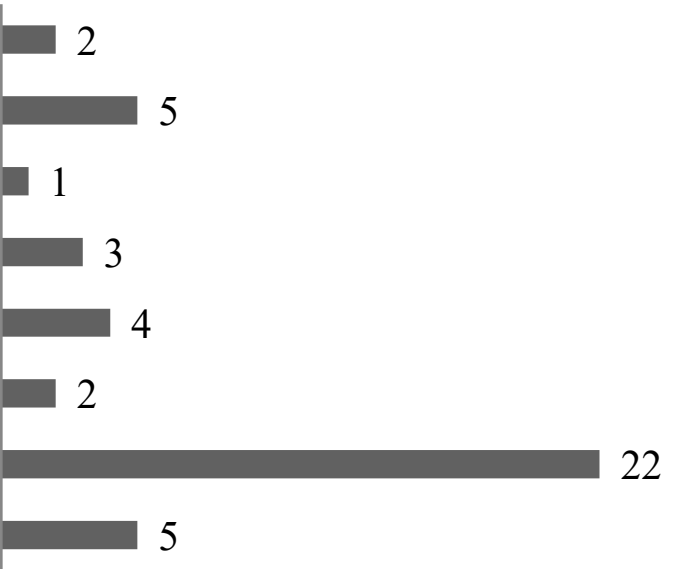

Рис. Распределение предприятий г. Краснодара по количеству работников в процентном соотношении прошедших профессиональное обучение за последние пять лет 
на основании их профессиональных, деловых и нравственных качеств, что делает механизмы повышения квалификации и переподготовки кадров максимально значимыми.

Принцип подбора кадров на основании их профессиональных, деловых и нравственных качеств реализуется посредством:

- выдвижения и продвижения кадров на основе исключительно их профессионального мастерства, компетентности и личных заслуг;

- объективности руководителей органов региональной исполнительной власти при определении уровня профессионализма и компетентности работников и принятии на этой основе соответствующих кадровых решений;

- организации «прозрачной» системы конкретных и ясных критериев оценки профессиональных, деловых и нравственных качеств при подборе и расстановке кадров;

- полной ликвидации субъективизма и протекции при назначениях на общественно значимые должности;

- активного использования легитимных кадровых технологий оценки персонала - конкурсов, испытаний, аттестаций, квалификационных экзаменов и пр.

Конечный итог применения данного принципа - последовательная деятельность, направленная на снижение, уровня безработицы выпускников вузов, а также лиц, не имеющих продолжительного профессионального опыта. Очевидно, что данные целевые установки могут быть достигнуты исключительно при соблюдении общей логики кадрового менеджмента.

В целом, разрешения очерченного круга проблем требует системного, взвешенного подхода, его стратегически выверенной реализации. Подводя итог, сформулируем некоторые заключения.

В настоящее время процессы, протекающие на рынке труда, связаны с постоянным усложне- нием содержания трудовой профессиональной деятельности.

Сегодня работодатель заинтересован в персонале, последовательно повышающем уровень своего профессионального мастерства, расширяющем спектр знаний, умений. В перспективе и данная тенденция уже сегодня представляется все более объективной и безусловной - для того, чтобы быть востребованным на рынке труда явно недостаточно наличие диплома и круга теоретических знаний. Более того, даже специалисты, имеющие определенный опыт работы, не могут быть застрахованы от увольнения по причине не полного соответствия занимаемой должности.

При этом отличительно чертой управления в области подготовки, переподготовки и повышения квалификации кадров является осуществление профессиональной подготовки за счет средств персонала.

Все это в комплексе вызывает объективную необходимость реализации практики переподготовки и повышения квалификации: рынок труда делает востребованными только тех специалистов, которые способны к постоянному совершенствованию своего профессионального мастерства, заинтересованы в том, чтобы расширять спектр своих умений в контексте смежных профессиональных областей. Кроме того, продвижение по карьерной лестнице в большинстве случаев непосредственным образом связано с рассматриваемой практикой: карьерный рост сопряжен с динамикой профессионального знания в той или иной области.

Таким образом, уже в кратко- и среднесрочном прогнозировании практика повышения квалификации и переподготовки имеет дополнительные импульсы своего развития: таковы требования рынка труда в условиях рыночной экономики.

\section{Библиографический список}

1. Сорокин П.А. Человек. Цивилизация. Общество / Общ. ред., сост. и предисл. А. Ю. Согомонов: пер. с англ. Москва. 1992. 543 с.

2. Touraine Alain. Pourrons-nous vivre ensemble? Egaux et different. [Электронный ресурс] // Paris. 1997. URL: https://journals.openedition.org/plc/782 (дата обращения: 25.12.2018)

3. Выпускники экономических специальностей на рынке труда. Серия «Качественные исследования в экономике и демографии». Выпуск 9: Сборник статей / Под ред. И.Е. Калабихиной.- М.: Экономический факультет МГУ имени М.В. Ломоносова, 2015. 200 с.

4. Заславская Т.И., Шабанова Т.Н. Неправовые трудовые практики и социальные трансформации в России // Социологические исследования. 2002. № 6. С. 3-17. 
5. Ананченкова П.И., Константинов В.М. Развитие образовательных услуг в сфере переподготовки и повышения квалификации кадров для малого и среднего бизнеса // Труд и социальные отношения. 2014. №9. С. 106-121.

6. Вукович Г.Г. Влияние состояния рынка труда на переподготовку рабочих кадров и обеспечение эффективной занятости // Вестник алтайской академии экономики и права. - 2011. № 4 (22). С. 9-12.

7. Фатхутдинов Р.А. Инновационный менеджмент: учебник для вузов. 6-е изд., испр. и доп. Санкт-Петербург. 2008. $448 \mathrm{c}$.

8. Груздева М.Л. Дополнительное информационное образование в системе повышения квалификации специалистов // Дополнительное образование и воспитание. 2006. № 10. С. 52-55.

9. Агаева А.Н., Ледовская М.Е. Подходы кадрового консалтинга к повышению квалификации и обучению персонала организации // Вестник белгородского университета кооперации, экономики и права. 2012. № 4 (44). C. 224-228.

10. Занятость и безработица в Российской Федерации в ноябре 2018 года [Электронный ресурс] // Федеральная служба государственной статистики: [сайт].- URL: www.gks.ru/bgd/free/B04_03/IssWWW.exe/Stg/d01/231. htm (дата обращения: 25.12.2018)

11. Крепс Т.В., Наруш В.В. Трудоустройство выпускников экономических вузов: проблемы и пути их решения // Инновации и инвестиции. 2018. № 12. С. 112-115.

12. Наумов А.С. Модернизация российской экономики в условиях трансформации социальной структуры общества //Экономические науки. 2018. № 8 (165). С. 19-23.

13. Чанышев А.С. К вопросу о правовом регулировании рабочего времени: быть ли четырехдневной рабочей неделе? // Бизнес в законе. Экономико-юридический журнал. 2014. № 6. С. 20-23.

14. Золотов А.В. Сокращение рабочего времени как закон-тенденция развития капиталистического производства // Проблемы современной экономики. 2016. № 3(59). С. 51-56.

15. Дырин С.П. Состояние подготовки, переподготовки и повышения квалификации кадров на современных предприятиях // Интеграция образования. 2005. № 3. С. 61-65.

16. Бабаева Э.Т. Зарубежный опыт переподготовки и повышения квалификации персонала // Наука 21 века: вопросы, гипотезы, ответы. 2014. № 6. С. 138-141.

17. Дырин С.П. Управление персоналом: многовариантный характер современной российской практики. Санкт-Петербург, 2008. 216 с. 